\title{
DERIVA DE CÉLULAS EPITELIALES DE TEJIDO DE PIEL DESCONGELADO DE OVIS CANADENSIS MEXICANA PARA LA FORMACIÓN DE UN BANCO DE GERMOPLASMA
}

\author{
María del Carmen NAVARRO-MALDONADO, ${ }^{1}$ SARAHí HERNÁNDEZ-MARTÍNEZ, ${ }^{1}$ JosÉ Roberto \\ VÁZQUEZ-AVENDAÑO, ${ }^{1}$ José LuIS MARTÍNEZ-IBARRA, ${ }^{1}$ NATHALY LILIÁN ZAVALA-VEGA, ${ }^{1}$ BÁRBARA \\ VARGAS-MIRANDA, ${ }^{2}$ JUAN ARTURo RIVERA-REBOLLEDO ${ }^{3}$ y DEMETrIo Alonso AMBRÍZ-GARCÍA ${ }^{1}$
}

\begin{abstract}
${ }^{1}$ Departamento de Biología de la Reproducción, ${ }^{2}$ Departamento de Ciencias de la Salud, Universidad Autónoma Metropolitana Unidad Iztapalapa Av. San Rafael Atlixco Núm. 186 Col. Vicentina Del. Iztapalapa C.P. 09340, ${ }^{3}$ Dirección General de Zoológicos y Vida Silvestre, Secretaría del Medio Ambiente del Distrito Federal. México D. F. <carmennavarro2006@yahoo.com.mx>, <neverblackland@hotmail.com>, <robertmizer@gmail.com>, <luisjose02@hotmail.com>, <plantitafrondosa@hotmail.com>, <bvm@xanum.uam.mx>, <jarturorivera@sma.gmail.com>, <deme@xanum.uam.mx>
\end{abstract}

Recibido: 09/01/2015; aceptado: 27/03/2015

Navarro-Maldonado M. C., Hernández-Martínez S., VázquezAvendaño J. R., Martínez-Ibarra J. L., Zavala-Vega N. L., Vargas-Miranda B., Rivera-Rebolledo J. A. \& Ambríz-García D. A. 2015. Deriva de células epiteliales de tejido de piel descongelado de Ovis canadensis mexicana para la formación de un banco de germoplasma. Acta Zoológica Mexicana (n. s.), 31(2): 275-282.

RESUMEN. En nuestro país existen diversas especies de mamíferos de interés ecológico que ostentan alguna categoría de riesgo o peligro de extinción. Con la finalidad de resguardar la información genética de estas especies se han desarrollado técnicas de conservación ex situ, las cuales son componentes fundamentales de programas de conservación global que contemplan operaciones de almacenamiento del genoma. El almacenamiento se lleva a cabo mediante las colecciones de células y tejidos incorporados a bancos de germoplasma, que son una alternativa eficaz y próxima para hacerle frente al panorama crítico que sufre la fauna silvestre amenazada. En el presente trabajo se derivaron por vez primera en México, células epiteliales (queratinocitos) y de tejido conectivo (fibroblastos) a los 28 días de cultivo, a partir de piel de Ovis canadensis mexicana post-congelación de 54 días, para la formación de bancos de germoplasma.

Palabras clave: banco de germoplasma, células epiteliales, borrego cimarrón.

\section{INTRODUCCIÓN}

De acuerdo con la Lista Roja de Especies Amenazadas de la Unión Internacional para la Conservación de la Naturaleza (IUCN), han desaparecido 797 especies de fauna silvestre, 3801 están en franco peligro de extinción, 5566 están amenazadas de extinción y 9898 están en estatus de vulnerable (IUCN 2011). México ocupa el quinto lugar entre los diecisiete países con mayor megadiversidad del mundo, al contar con 108,519 especies descritas, las cuales representan el $10 \%$ de la biodiversidad mundial (CONABIO-CONANP 2010). Es primer lugar en reptiles, segundo lugar en mamíferos, tercer lugar en anfibios
Navarro-Maldonado M. C., Hernández-Martínez S., VázquezAvendaño J. R., Martínez-Ibarra J. L., Zavala-Vega N. L., Vargas-Miranda B., Rivera-Rebolledo J. A. \& Ambríz-García D. A. 2015. Epitelial cells derived from Ovis canadensis mexicana thawed skin tissue for a germplasm bank. Acta Zoológica Mexicana (n. s.), 31(2): 275-282.

ABSTRACT. Several mammal species of ecological interest in our country boast some category of risk or danger of extinction. With the purpose of guarding the genetic information of these species, researchers have developed techniques of ex situ conservation, which are key components of global conservation programs that contribute for the storage of the genome. This storage is carried out through the collection of cells and tissues embedded in germplasm banks, which are the most efficient solution to the critical panorama of the threatened wild fauna. In the present work, for the very first time in Mexico, epithelial (keratinocytes) and connective tissue (fibroblasts) cells were derived in culture on day 28, from Ovis canadensis mexicana after 54 days thawed skin tissue, to create a germplasm bank.

Key words: germplasm bank, epithelial cells, bighorn sheep.

y cuarto lugar en flora. Desafortunadamente, de esta diversidad de especies de fauna silvestre, un gran número ostenta alguna categoría de riesgo o peligro, por lo que 11,000 especies de mamíferos silvestres han sido resguardadas bajo protección especial por la Norma Oficial Mexicana (NOM-059-SEMARNAT-2010). Entre estas especies, al borrego cimarrón (Ovis canadensis) la Convención sobre Comercio Internacional de Especies Amenazadas de Fauna y Flora Silvestre (CITES), lo coloca como especie sujeta a protección especial y la IUCN como de preocupación menor, debido a la destacada reducción de sus poblaciones. 
El borrego cimarrón es una especie emblemática de nuestro país, originario de Eurasia que llegó al continente americano en el pleistoceno, a través de grandes corredores biológicos por la glaciación (Instituto Nacional de Ecología Dirección General de Vida Silvestre SEMARNAT 2000). De las siete subespecies originales de cimarrón, tres se distribuyen en México: borrego cimarrón mexicano (O. c. mexicana) al Noroeste de Sonora e Isla Tiburón en el Mar de Cortés; borrego peninsular (O. C. cremnobates) en los dos tercios hacia el norte de Baja California; y el borrego cimarrón weemsi (O. c. weemsi) en el tercio sureño de Baja California Sur; mientras que en Chihuahua y Coahuila únicamente se encuentra en criaderos (SEMARNAT 2003; The IUCN Red List of Threathened Species 2011.2). Se tiene el dato de que en Sonora el censo era de 575 cimarrones (machos y hembras) para el año 2011, distribuidos en 13 sierras de 6 municipios (González et al. 2011).

Debido a las actividades antropogénicas y a la explotación indiscriminada de los recursos naturales nacionales, se han generado cambios drásticos y alarmantes en las condiciones del hábitat de las especies de fauna silvestre, originando con ello un desplazamiento y disminución de sus poblaciones. Dentro de los factores de vulnerabilidad, encontramos la cacería, la cual ha llegado a considerar al borrego cimarrón un trofeo "altamente selecto", debido a su llamativa cornamenta. Esta actividad se desarrolla de manera legal e ilegal, en cuanto a la legal, los cazadores que se apegan a la normatividad oficial pueden llegar a pagar por un permiso desde 35,000 hasta 300,000 dólares. (Smith \& Krausman 1988), mientras que los cazadores furtivos pueden representar un mayor riesgo a la especie a causa de su incontrolada actividad.

Debido a la importancia en el equilibrio ecológico que el borrego cimarrón tiene, su situación actual obliga a crear estrategias que disminuyan el riesgo de extinción. Además, la conservación de esta especie en el país, debe resultar en beneficios sociales y económicos derivados de su uso sustentable, coadyuvando en su conservación (Instituto Nacional de Ecología, Secretaría de Medio Ambiente y Recursos Naturales-SEMARNAT 2007). Sin embargo, hasta el momento la investigación generada en cuanto a esta especie estriba principalmente en estudios poblacionales, anatómicos y sanitarios (Besser et al. 2013; Smith et al. 2014).

En lo concerniente a la reproducción del borrego cimarrón, los avances científicos han sido solo a nivel de seguimiento del ciclo estral y gestación, mediante técnicas no invasivas de determinación de hormonas esteroideas en heces y en estudios de conducta sexual en cautiverio (Soto 2006). Estudios más avanzados efectuados en Italia permitieron reproducir a otra especie de borrego silvestre: el muflón (Ovis orientalis musimon) mediante la clonación por transferencia nuclear y en Estados Unidos se hicieron intentos para reproducir Ovis argali con la misma biotecnología (Loi et al. 2001; Williams et al. 2006).

En México, no existen datos concretos sobre la aplicación de las biotecnologías reproductivas, ni la creación de bancos de germoplasma que ofrezcan alternativas de reproducción y conservación de esta especie silvestre (Ovis canadensis mexicana), solo se ha documentado la intención de asistir la reproducción del borrego cimarrón de Sonora (UNAM 2009).

Con la finalidad de resguardar la información genética de estas especies, se han desarrollado técnicas de conservación ex situ, las cuales son componentes fundamentales de programas de conservación global que contemplan operaciones de almacenamiento del genoma. El almacenamiento se lleva a cabo mediante las colecciones de células y tejidos incorporados a los bancos de germoplasma (Irondo-Alegría 2001). Actualmente estos bancos son una alternativa más, para hacer frente al panorama crítico que sufre la fauna silvestre amenazada. Sin embargo, para llevar a cabo reproducción animal asistida mediante técnicas de transferencia nuclear o para la creación de bibliotecas genómicas, es necesario entender y aplicar adecuadamente las técnicas de conservación de material biológico (Ávila-Portillo et al. 2006; León-Quinto et al. 2011). Una de estas técnicas es la criopreservación en la cual se almacenan células germinales, somáticas o tejidos, en crioprotectores a bajas temperaturas, permitiendo que a la descongelación, se logren restablecer sus condiciones fisiológicas normales con una considerable tasa de viabilidad (Vásquez et al. 2011).

Para tejidos y células somáticas, se utilizan agentes protectores que se clasifican, de acuerdo a la permeabilidad celular, como penetrantes y no penetrantes. Entre los penetrantes se encuentra uno de los crioprotectores más utilizado, el DimetilSulfóxido $\left(\mathrm{CH}_{3} \mathrm{SOCH}_{3}\right)$ o DMSO (Fernández et al. 2009), el cual, si es utilizado a concentraciones adecuadas, permite conservar tejidos y células congeladas (León-Quinto et al. 2011).

Los bancos de tejidos y células somáticas están ligados a las condiciones de su cultivo, siendo éste un factor de éxito en el desarrollo de colonias celulares. Otro factor de éxito es el sistema utilizado de deriva celular a partir de tejidos, como es el sistema mecánico que utiliza explantes (Han et al. 2003) o la disgregación enzimática mediante el uso de colagenasa tipo I o tipo II, o una combinación de ambas (Mauger et al. 2006). También es determinante la adición a los medios de cultivo, de factores mitóticos y de crecimiento celular como el EGF (Epidermal Growth Factor) y el FGF (Fibroblast Growth Factor) (Bhora et al. 1995). En el caso del EGF, se sabe que actúa como 
mitógeno, retrasa la senescencia de los queratinocitos y favorece su migración en cultivos (Mujaj et al. 2010).

Finalmente, la adición de sueros en los medios de cultivo de células somáticas también influye. Por ejemplo, en el caso de las células epidérmicas de humano derivadas en cultivos primarios para su uso en la reposición de tejidos dañados, se sabe que se corren riesgos con el uso de SFB (Suero Fetal Bovino) o FCS (Fetal Calf Serum) como suplemento, ya que conlleva a la formulación de medios con componentes indefinidos, que pueden contener agentes infecciosos causales de zoonosis (priones, agentes virales) o causar reacciones alérgicas en los pacientes por las proteínas de origen animal presentes (Morimoto et al. 2011). Por lo que algunos autores optan por excluir su uso en los sistemas de cultivo, con buenos resultados si los medios de cultivo incluyen factores de crecimiento como el EGF y el IGF-I (Insulin Like Growth Factor-I) (Mujaj et al. 2010).

Por ello es importante considerar los medios de cultivo, suplementos de los mismos y las condiciones del manejo de las células que serán incluidas en los bancos de germoplasma.

La formación de bancos de germoplasma de células somáticas en especies silvestres, requiere de la colecta de tejidos de animales vivos, generalmente en cautiverio, de los que solo pueden obtenerse tejidos de muy pequeñas dimensiones, generalmente piel, para evitar dañarlos. Las células somáticas podrán entonces ser utilizadas en la producción de embriones por transferencia nuclear, que utiliza fibroblastos derivados de diversos tejidos como la piel y las células de la granulosa, entre otras (Folch et al. 2009; León-Quinto et al. 2011; Kurd et al. 2013; Liu et al. 2013).

El objetivo del presente trabajo fue derivar, por vez primera en México, células epiteliales y de tejido conectivo a partir de piel de borrego cimarrón (Ovis canadensis mexicana) post-congelación, para establecer líneas celulares donadoras de información genética que podrán ser utilizadas en la producción de embriones por transferencia nuclear y en la formación de bancos de germoplasma.

\section{MATERIALES Y MÉTODOS}

Una biopsia de piel $\left(1 \mathrm{~cm}^{3}\right)$ fue obtenida de un ejemplar vivo de borrego cimarrón (Ovis canadensis mexicana) macho adulto del Zoológico de Chapultepec perteneciente a la Dirección General de Zoológicos y Vida Silvestre (DGZVS), de la Secretaría del Medio Ambiente en el Distrito Federal, México. La biopsia fue transportada al laboratorio durante 1 hora en PBS (Phosphated Buffered Saline) suplementado ( $2 \%$ de Antibac-Antifun que contiene 10,000 unidades de Penicilina, $10 \mathrm{mg}$ de Sulfato de
Estreptomicina y $25 \mu \mathrm{g}$ de Anfotericina B por mL) dentro de un termo con hielo. A su llegada al laboratorio, el tejido de piel se desinfectó con cloro al 1\% y se lavó 4 veces en PBS. El tejido se dividió en tres fragmentos iguales de aproximadamente $0.30 \mathrm{~cm}^{3}$ cada uno. Siguiendo la metodología de Amores et al. (2014) con algunas modificaciones, uno de los fragmentos se colocó en un criotubo que contenía $1.5 \mathrm{~mL}$ de medio de congelación de células a base de dimetilsulfóxido (DMSO 7\%, SFB 15\% en Medio Mínimo Esencial o DMEM, In Vitro, S.A.). El criotubo fue enfriado a $4{ }^{\circ} \mathrm{C}$ durante 1 hora y se congeló $24 \mathrm{~h} \mathrm{a}-20{ }^{\circ} \mathrm{C}$ antes de ser almacenado por 54 días a -80 ${ }^{\circ} \mathrm{C}$. Posteriormente a este período, el tejido fue descongelado a $37^{\circ} \mathrm{C}$ por $10 \mathrm{~min}$, se lavó en PBS suplementado y se disgregó durante 3 h enzimáticamente utilizando $0.2 \%$ Colagenasa tipos I y II (Collins et al., 2011). El tejido no digerido se sembró como explante en DMEM suplementado (88\% DMEM, 10\% SFB, 2\% Antifun-Antibac, $\mathrm{pH}$ 7) a $37^{\circ} \mathrm{C}, 5 \%$ de $\mathrm{CO}_{2}$ y $60 \%$ de humedad relativa. A los 3 días fue transferido a una caja nueva con medio de cultivo adicionado con $1 \mu \mathrm{g} / \mathrm{mL}$ de EGF. A los 14 días de cultivo se efectuó el primer pasaje celular tripsinizando las células (tripsina-verseno 0.05\%/0.05\%); la mitad de la población celular se criopreservó y la otra mitad se resembró para efectuar los pasajes celulares subsecuentes. Se realizaron un total de 5 pasajes celulares, de los cuales todas las células derivadas de cada pasaje se criopreservaron en 1.5 $\mathrm{mL}$ de medio de congelación de células a base de DMSO (In Vitro, S.A.), a $-80{ }^{\circ} \mathrm{C}$ por un año y 3 meses.

Se elaboró una gráfica (Fig. 3) con los datos de la población celular obtenida expresada como porcentaje de confluencia durante los días que correspondieron, desde la descongelación del fragmento de tejido y siembra de las células de Ovis canadensis mexicana (Día 0), hasta los diferentes pasajes celulares $\left(1^{\circ}\right.$ al $\left.5^{\circ}\right)$ efectuados.

La técnica de inmunofluorescencia se realizó siguiendo el método de Antonio-Rubio et al. (2013) con las siguientes modificaciones; las células se cultivaron sobre cubreobjetos tratados con poly L-lisina incubados en cajas de petri estériles con medio de cultivo en condiciones estándar de temperatura $\left(38{ }^{\circ} \mathrm{C}\right)$, en una atmosfera de $5 \%$ $\mathrm{CO}_{2}$ y humedad relativa. Después de 7 días de cultivo, se retiró el medio de cultivo e inmediatamente después se lavó con $1 \mathrm{~mL}$ de PBS 1X (DPBS Gibco 10X, pH 7.1) durante 5 min a temperatura ambiente, teniendo precaución de mantener húmeda la muestra. Las células se fijaron con paraformaldehído (Sigma Aldrich) al 4\% en PBS $1 \mathrm{X}$, seguido de 3 lavados con PBS $1 \mathrm{X}$ de 5 min cada uno. Las cajas fueron transportadas con $1 \mathrm{~mL}$ de PBS en una hielera, hasta el laboratorio.

Mediante succión por vacío, se retiró el PBS de las cajas y se colocó Triton X-100 (Sigma Aldrich) por 2 min 
para permeabilizar las membranas celulares, permitiendo así que los anticuerpos penetraran de manera adecuada y almacenaran los antígenos correspondientes. Se hizo un lavado de 5 min con PBS 1X para eliminar el detergente, y las células se incubaron durante $2 \mathrm{~h}$ con albúmina (Sigma Aldrich) al 1\% en PBS, con el fin de evitar la presencia del antígeno en lugares distintos a aquel en que se quiere detectar. Posteriormente, las células control positivo se incubaron a $4{ }^{\circ} \mathrm{C}$ durante toda la noche con el anticuerpo primario anti-Citokeratina14 conejo (Abcamab15461) (dilución 1:250 en PBS 1X suplementado con albumina al 1\%); el control negativo se almacenó de la misma manera, sin embargo, no se le agregó el anticuerpo primario para identificar la especificidad de la marca. Al día siguiente, las muestras se lavaron 4 veces con PBS $1 \mathrm{X}$ y se bloqueó con albumina al $1 \%$ durante 15 min, después se retiró la albumina, se colocó el anticuerpo secundario Cy3 anti-conejo, dejando reposar en oscuridad durante 1 $\mathrm{h}$ a temperatura ambiente. Finalmente, las cajas se lavaron 4 veces con PBS $1 X$. Los cubreobjetos tratados con poly L-lisina se montaron sobre portaobjetos (Superfrost-plus, Electron Microscopy Sciences) en medio acuoso (Fluorescence Mounting Medium Dako®) y se guardaron a 4 ${ }^{\circ} \mathrm{C}$ hasta secarse, esto para ser visualizados en microscopio de fluorescencia (Olympus BX41). El anticuerpo Cy3 fue excitado usando un láser de $494 \mathrm{~nm}$.

\section{RESULTADOS}

Con la muestra colectada, se obtuvieron los primeros fibroblastos de Ovis canadensis mexicana, que se derivaron a los 3 días de cultivo, con una confluencia del 10\%, pero se dejó crecer su población por 4 días más. A los 7 días de cultivo, se realizó un cambio de medio en la caja (caja 1), retirando el tejido de piel sobrenadante y resembrándolo como explante en una nueva caja (caja 2), en la que siguieron derivándose fibroblastos hasta cumplir 7 días más de cultivo, momento en el cual alcanzaron una confluencia del 30\% y se les volvió a cambiar el medio suplementado con EGF, pero la población celular fue muy baja en la caja 2 por lo que se descartó. En la caja 1 en cambio, la población celular continuó multiplicándose y alcanzó un $40 \%$ de confluencia al día 14 de cultivo, efectuando el primer pasaje celular, recuperando los fibroblastos por tripsinización y lavándolos por centrifugación en PBS. Una parte de la población celular (300,000 células) fue criopreservada a $-80^{\circ} \mathrm{C}$ en $\mathrm{DMSO}$, mientras que la otra mitad fue resembrada en cajas nuevas. Para aprovechar todas las células derivadas, durante el primer pasaje celular, a las cajas tripsinizadas se les agregó más medio ( $3 \mathrm{~mL}$ ) con la posibilidad de que si había fibroblastos adheridos a su base, proliferaran y continuaran con los pasajes subsecuentes, como de hecho sucedió. Es así que los pasajes celulares se efectuaron por duplicado cada 7 días haciendo un total de 5 pasajes y criopreservando una parte de la población celular obtenida de cada pasaje. El $2^{\circ}$ pasaje se efectuó a los 21 días. Al día 28 de cultivo se efectuó el 3er pasaje celular y se observó que además de los fibroblastos (células de tejido conectivo) (Fig. 1) se derivaron otros tipos celulares (células epiteliales-queratinocitos) (Fig. 2) con una confluencia del $40 \%$. El $4^{\circ}$ pasaje celular se efectuó el día 35 a una confluencia de más del $50 \%$ y el día 42 correspondió al $5^{\circ}$ pasaje celular que alcanzó una confluencia de más del $60 \%$. Es decir que los tipos celulares obtenidos en los pasajes $4^{\circ}$ al $5^{\circ}$, alcanzaron una confluencia del $50-70 \%$ y se criopreservaron a $-80{ }^{\circ} \mathrm{C}$ por un año y 3 meses (Fig. 3 ).

Originalmente, la identificación de las células de Ovis canadensis mexicana derivadas en este trabajo en los cultivos primarios y en cada pasaje celular, se llevó a cabo mediante la comparación de las fotografías tomadas a las células, con las de las células obtenidas por otros autores consultados en la literatura (Calderón \& Calderón 2002; Concha et al. 2002).

Posteriormente, se enviaron las fotografías de las células de Ovis canadensis mexicana obtenidas en este trabajo, a uno de los autores de la literatura consultada, el Dr. Miguel Concha, Director de la Escuela de Graduados, Facultad de Medicina de la Universidad Austral de Chile, quien nos dio su opinión sobre la identidad de las mismas, señalando que en efecto eran altamente compatibles con queratinocitos epidérmicos, que era posible reconocer dos o tres áreas con apariencia de perlas córneas correspondientes a formaciones de queratinocitos en estado de diferenciación terminal y que las células de O. c. mexicana eran análogas a las células que aparecen en el trabajo de Calderón \& Calderón (2002) (Correo electrónico recibido el 2 de marzo 2015).

Finalmente, el ensayo de inmunofluoresencia efectuado, reveló que las células obtenidas correspondían a queratinocitos epidérmicos (Fig. 4).

\section{DISCUSIÓN}

La metodología para la deriva celular a partir de tejido de piel de Ovis canadensis mexicana, fue similar a la reportada por Collins et al. (2011) quienes utilizaron colagenasa tipos I y II, pero además utilizaron ADNasa I para disgregar una muestra de piel de ratón adulto, obteniendo la deriva de fibroblastos y queratinocitos. En nuestro trabajo, utilizando únicamente colagenasa tipos I y II, se logró la deriva y proliferación de fibroblastos de piel de borrego cimarrón macho adulto.

El EGF y otros péptidos mitogénicos relacionados, regulan el crecimiento y la diferenciación celular en 


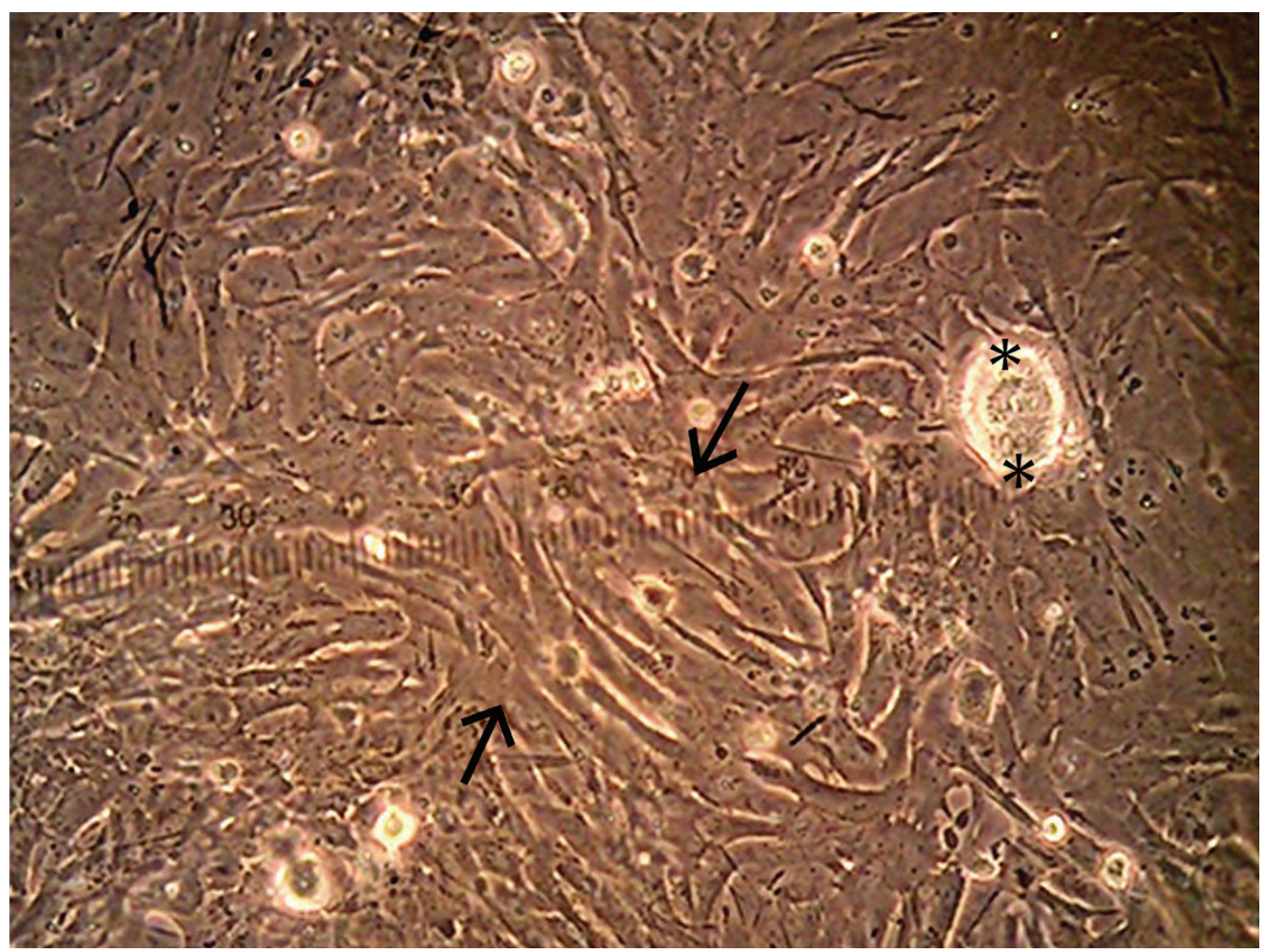

Figura 1. Día 28 de cultivo. Antes de efectuar el tercer pasaje celular. Las flechas señalan fibroblastos y con asteriscos se delimita la presencia de una perla córnea (40X).

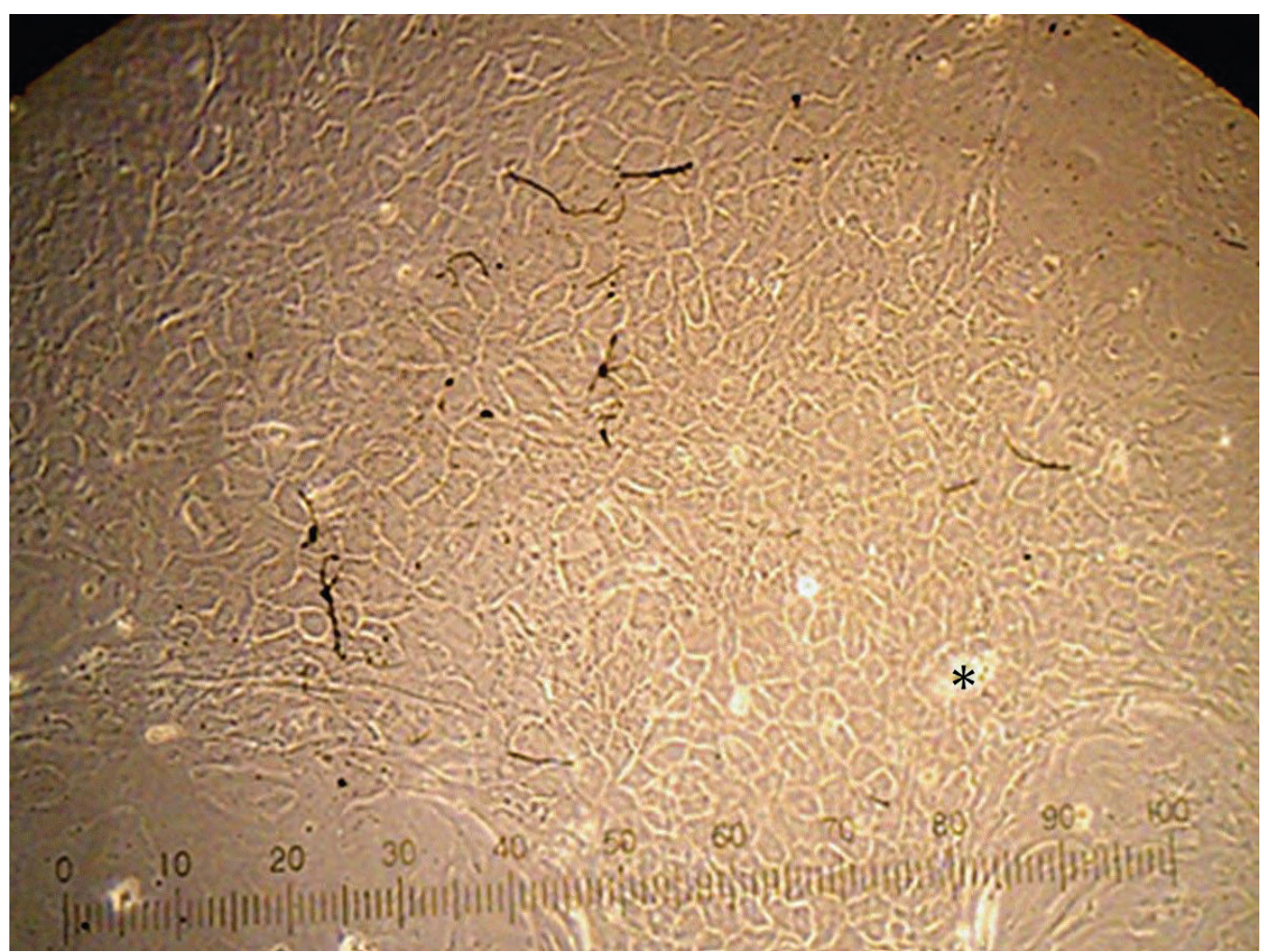

Figura 2. Día 28 de cultivo. Antes de efectuar el tercer pasaje celular. La imagen muestra células conglomeradas en forma de escama que corresponden a células epidérmicas en monocapa (queratinocitos). El asterisco muestra una perla córnea (10X). 


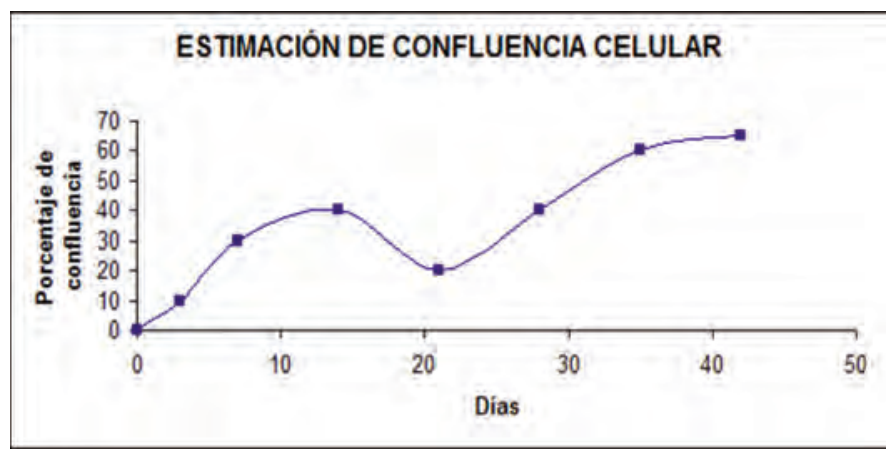

Figura 3. Estimación de la confluencia en cultivos de células de piel de Ovis canadensis mexicana descongelada. Día 0: Descongelación y siembra. Día 3: Presencia de las primeras células (10\% confluencia). Día 7: Primer cambio de medio (30\% confluencia). Día 14: Primer pasaje celular (40\% confluencia). Día 21: Segundo pasaje celular.

Día 28: Tercer pasaje celular: Se observan las primeras células epiteliales (40\% confluencia). Día 35: Cuarto pasaje celular (>50\% confluencia). Día 42: Quinto pasaje celular (>60\% confluencia) y criopreservación de células a $-80^{\circ} \mathrm{C}$.

los tejidos que se regeneran en los procesos de reparación y en el desarrollo de placenta y feto; uniéndose a su receptor (EGFR) en la superficie celular, a través de la transducción de señales en la membrana plasmática y por la activación subsecuente de vías de señalización en la célula, así como por la inducción de la expresión génica temprana (Rijken et al. 1994; Yun et al. 2013). Kim et al. (2014) demostraron que la presencia de EGF en los cultivos celulares favorece la producción de colágena I y hialuronano por los fibroblastos, elementos que son necesarios para la producción de la matriz extracelular y la producción de tejido epitelial. Por lo que en nuestro estudio, la adición de EGF pudo propiciar la diferenciaron de células epiteliales.

Por otro lado, en este estudio fue posible derivar fibroblastos y células epiteliales (queratinocitos) en cultivos primarios, a partir de piel de Ovis canadensis mexicana que había sido congelada por 54 días a $-80{ }^{\circ} \mathrm{C}$.

Considerando que en México no es fácil adquirir muestras de piel de animales silvestres vivos, como el borrego cimarrón, un buen sistema de preservación es indispensable para obtener el mayor provecho a la muestra. De ahí que nuestros resultados, en términos de haber obtenido la deriva celular a partir de tejido de piel criopreservado en DMSO, son similares a lo reportado por Wood et al. (2014) quienes, utilizando diferentes crioprotectores en tejidos para injertos de piel, obtuvieron buenos resultados con el DMSO.

Debido a sus propiedades criopreservantes, el DMSO se utiliza para minimizar el daño celular durante la congelación, porque penetra a la célula y une las moléculas de agua, bloquea el eflujo de agua previniendo la deshidra- tación, mantiene estable el pH intracelular y la concentración de sales, reduce el tamaño del hielo extracelular que se forma durante el proceso y que daña la matriz extracelular y la membrana celular, evitando así que se alteren las propiedades de barrera de los tejidos porque previene la formación de cristales de hielo que afectan las propiedades mecánicas de los tejidos de piel utilizados como injertos (Amores et al. 2014; Wood et al. 2014).

Por su parte, Wiedemann et al. (2012) pudieron obtener células germinales viables (ovocitos) de leonas (Panthera leo) en cautiverio, a partir de tejido ovárico congelado en criomedio a base de etilenglicol y sacarosa, y luego descongelado gradualmente $(-140,-40,-8,-4$, $1{ }^{\circ} \mathrm{C}$ ), formando así un banco de germoplasma.

La combinación de las metodologías efectuadas en este trabajo, como fueron la utilización de DMSO como crioprotector, la congelación gradual $\left(4,-20 \mathrm{y}-80{ }^{\circ} \mathrm{C}\right)$ del tejido de piel de Ovis canadensis mexicana, la digestión enzimática (Colagenasas I y II), la disgregación mecánica (explante) y la adición de EGF a los medios de cultivo celular, permitieron la deriva de fibroblastos de piel de adulto. La digestión enzimática y el uso de EGF, favoreció además su diferenciación en células epiteliales (queratinocitos).

Se observó que las células derivadas de piel de $O$. $c a$ nadensis mexicana adulto descongelada, alcanzaron apenas el $40 \%$ de confluencia hacia el día 14 de cultivo, a diferencia de lo observado en células derivadas de piel fresca de ovino doméstico (Ovis aries) joven y células derivadas de pulmón fresco de ovino doméstico adulto, las cuales a los 7 días del cultivo inicial alcanzaron una confluencia de más del 90\% y continuaron proliferando hasta el $9^{\circ}$ pasaje, momento a partir del cual, la confluencia fue en decremento (Datos no publicados).

Si bien en este trabajo se obtuvieron células de borrego silvestre adulto, mientras que en un trabajo previo se obtuvieron células de borrego doméstico joven (Datos no publicados), es poco probable que la baja confluencia observada en este trabajo (50 a 70\%) en los últimos pasajes celulares $\left(4^{\circ}\right.$ y $\left.5^{\circ}\right)$, se debiera al factor edad, como lo demuestran los trabajos efectuados en humanos por Wen et al. (2013), quienes no encontraron diferencias significativas en el índice mitótico, determinado por el número de células en mitosis a un tiempo determinado, entre fibroblastos de vagina de mujer joven vs. adulta (20-25 células por $16 \mathrm{~h}$ ). Por lo que podría explicarse que el proceso de congelación-descongelación de la piel de Ovis canadensis mexicana llevado a cabo en este trabajo, influyera en hacer más lenta la proliferación celular en los cultivos. Estos resultados difieren de lo reportado por Liu et al, (2011), quienes concluyeron que la congelación de células de ovino Mongol en DMEM suplementado con 10\% 


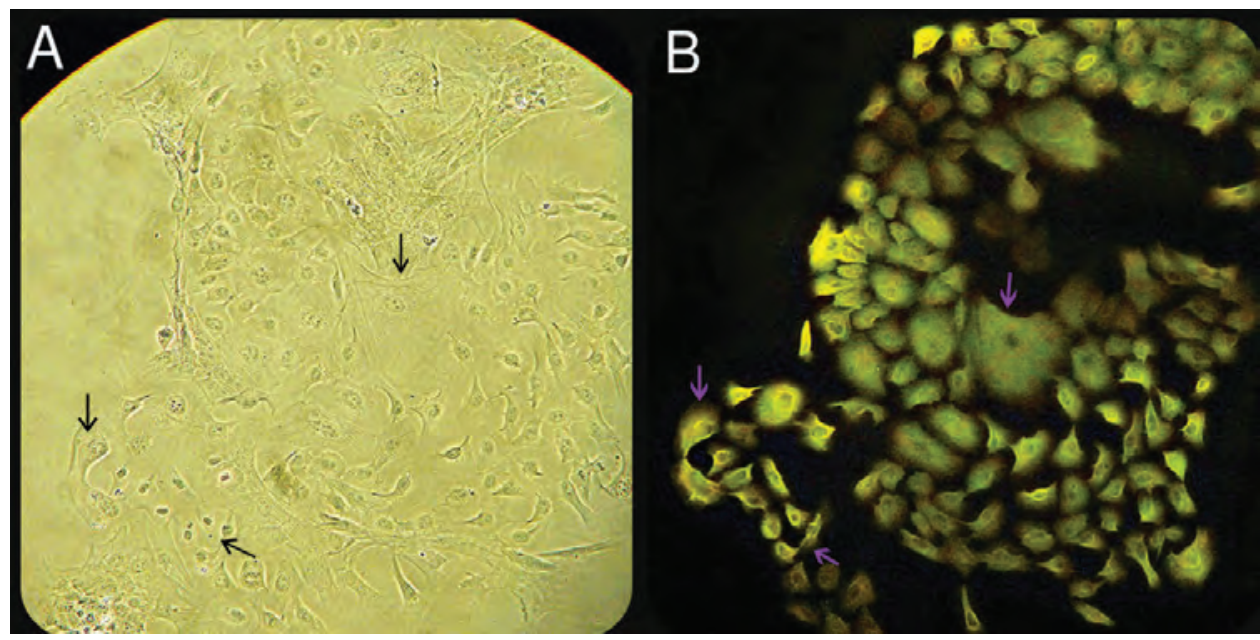

Figura 4. Día 21 de cultivo. Antes de efectuar el segundo pasaje celular. Las imágenes muestran una comparación del análisis inmunohistoquímico. (A) Células en cultivo observadas en campo claro. (B) Mismas células en cultivo observadas en microscopio de epifluorescencia, fluorescen ante la presencia del anticuerpo secundario Cy3 excitado por láser de $494 \mathrm{~nm}$. Las flechas muestran la presencia de células epidérmicas en monocapa (queratinocitos) (40X).

DMSO y 50\% SFB, tuvo poca influencia en la viabilidad de los fibroblastos descongelados, aunque no especifican el tiempo que permanecieron congeladas las células de este ovino doméstico.

En este trabajo se describe por primera vez, la posibilidad de formar un banco de germoplasma a partir de una muestra de piel de $O$. canadensis mexicana que fue criopreservada durante 54 días y de la cual se obtuvo la deriva de fibroblastos y células epiteliales, una vez descongelada la muestra.

AGRADECIMIENTOS. Los autores desean expresar su sincero agradecimiento al Dr. Marcos Cajero Juárez y a la Dra. Alejandra Soberano Martínez, de la Universidad Michoacana de San Nicolás de Hidalgo por su asesoría sobre el uso de colagenasa II para la disgregación enzimática de tejidos de piel de animales adultos. Asimismo, se agradece a la Dra. Norma Angélica Moreno Mendoza y a la M. en C. Tania Janeth Porras Gómez del Instituto de Investigaciones Biomédicas de la UNAM, por la asesoría y facilidades otorgadas para realizar las pruebas de inmunofluorescencia, para determinar la identidad de las células obtenidas. Agradecemos el apoyo del personal médico veterinario del Zoológico de Chapultepec. Las observaciones de tres revisores anónimos mejoraron el manuscrito.

\section{LITERATURA CITADA}

Amores, S., Domenech, J., Colom, H., Calpena, A. C., Clares, B., Gimeno, A. \& Lauroba, J. 2014. An improved cryopreservation method for porcine buccal mucosa in ex vivo drug permeation studies using Franz diffusion cells. European Journal of Pharmaceutical Sciences, 60: 49-54.

Antonio-Rubio, N. R., Porras-Gómez, J. T. \& Moreno-Mendoza, N. 2013. Identification of cortical germ cells in adult ovaries from three phyllostomid bats: Artibeus jamaicensis, Glossophaga soricina and Sturnira lilium. Reproduction, Fertility and Development, 25: 825-836.

Avila-Portillo, L. M., Madero, J. I., López, C., León, M. F., Acosta, L., Delgado, L. G. Gómez, C., Lozano, J. M. \& Reguero, T. 2006. Fundamentos de criopreservación. Revista Colombiana de Obstetricia y Ginecología, 57: 291-300.

Besser, T. E., Frances-Cassirer, E., Highland, M. A., Wolff, P., Justice-Allen, A., Mansfield, K., Davis, M. A. \& Foreyt, W. 2013. Bighorn sheep pneumonia: sorting out the cause of a polymicrobial disease. Preventive Veterinary Medicine, 108: 85-93.

Bhora, F. Y., Dunkin, B. J., Batzri, S., Aly, H. M., Bass, B. L., Sidaw, Y. A. N. \& Harmon, J. W. 1995. Effect of growth factors on cell proliferation and epithelialization in human skin, Journal of Surgical Research, 59: 236-244.

Calderón, V. W. \& Calderón V., R. 2002. Cultivo de queratinocitos humanos en monocapa. Revista Boliviana de Dermatología, 1: $11-14$.

Collins, C. A., Kretzschmar, K. \& Watt, F. M. 2011. Reprogramming adult dermis to a neonatal state through epidermal activation of b-catenin. Development, 138: 5189-5199.

Comisión Nacional para el conocimiento y uso de la biodiversidad (CONABIO) \& Comisión Nacional de Áreas Naturales Protegidas (CONANP) a través de la Secretaría de Medio Ambiente y Recursos Naturales (SEMARNAT). 2010.

Concha, M. M., Vidal, V. A. \& Salem Z., C. 2002. Producción de equivalentes dermo-epidérmicos autólogos para el tratamiento de grandes quemados y cicatrices queloideas. Cuadernos de Cirugía, 16: 41-47.

Fernández, A., Gonzalvo, M., Clavero, A., Ruiz, R., Zamora, S., Roldan, M., Rabelo, B., Ramírez, J., Yoldi, A. \& Castilla, J. 2009. Fundamentos de criobiología espermática para bancos de semen. Revista Asebir, 14: 17-25.

Folch, J., Cocero, M. J., Chesné, P., Alabart, J. L, Domínguez, V., Cognié, Y., Roche, A., Fernández-Arias, A., Martí, J. I., Sánchez, P., Echegoyen, E., Beckers, J. F., Bonastre, A. S. \& Vignon, X. 2009. First birth of an animal from an extinct subs- 
pecies (Capra pyrenaica pyrenaica) by cloning. Theriogenology. 71: 1026-34.

González, S. F., Tarango, A. L. A., Cantú, A. C., Uvalle, S. J., Marmolejo, M. J. \& Ríos, S. C. A. 2011. Estudio poblacional y de distribución del borrego cimarrón (Ovis canadensis mexicana, Merriam 1901) en Sonora. Revista Mexicana de Ciencias Forestales, 2: 63-75.

Han, Z. N., Chen, D. Y., Li, J. S., Sun, Q. Y., Wang, P. Y., Du, J. \& Zhang, H. M. 2003. Flow cytometric cell-cycle analysis of cultured fibroblasts from the giant panda, Ailuropoda melanoleuca. Cell Biology International, 27: 349-353.

Instituto Nacional de Ecología Dirección General de Vida Silvestre. 2000. Proyecto para la conservación, manejo y aprovechamiento sustentable del borrego cimarrón (Ovis canadensis) en México. Secretaría del Medio Ambiente, Recursos Naturales y Pesca (SEMARNAT) Instituto Nacional de Ecología. México, D.F.

Iriondo-Alegría, J. M. 2001. Conservación de germoplasma de especies raras y amenazadas. Investigación Agraria. Producción y Protección Vegetal, 16: 5-24.

Kim, M. S., Song, H. J., Lee, S. H. \& Lee, C. K. 20014. Comparative study of various growth factors and cytokines on type I collagen and hyaluronan production in human dermal fibroblasts. Journal of Cosmetic Dermatology, 13: 44-51.

Kurd, S., Zarei, M. A., Fathi, F., Ghadimi, T., Hakhamaneshi, M. S., \& Jalili, A. 2013. Production of cloned mice by nuclear transfer of cumulus cells. Avicenna Journal of Medical Biotechnology, 5: 186-92.

Lazzari, G., Wrenzycki, C., Herrmann, D., Duchi, R., Kruip, T., Niemann, H. \& Galli, C. 2002. Cellular and molecular deviations in bovine in vitro-produced embryos are related to the Large Offspring Syndrome. Biology of Reproduction, 67: 767-775.

Leon-Quinto, T., Simón, M. A., Sánchez, A., Martín, F. \& Soria, B. 2011. Cryobanking the genetic diversity in the critically endangered Iberian Lynx (Lynx pardinus) from skin biopsies. Investigating the cryopreservation and culture ability of highly valuable explants and cells. Cryobiology, 62: 145-151.

Liu, C. Q., Guo Y., Guan W. J. \& Ma Y. H. 2011. Establishment and characterization of a fibroblast cell line derived from Mongolian sheep. Animal Science Journal, 82: 215-222.

Liu, J., Yang, Z., Qiu, M., Luo, Y., Pang, M., Wu, Y. \& Zhang, Y. 2013. Developmental potential of cloned goat embryos from a SSEA3(+) subpopulation of skin fibroblasts. Cellular Reprogramming, 15: 159-65.

Loi, P., Ptak, G., Barboni, B., Fulka, J. Jr., Cappai, P. \& Clinton, M. 2001. Genetic rescue of an endangered mammal by cross-species nuclear transfer using post-mortem somatic cells. Nature Biotechnology, 10: 962-964.

Mauger, P. E., Le Bail, P. Y. \& Labbé, C. 2006. Cryobanking of fish somatic cells: optimizations of fin explant culture and fin cell $\mathrm{cr}-$ yopreservation. Comparative Biochemistry and Physiology, 144: 29-37.

Morimoto N., Takemoto S., Kanda N., Ayvazyan A., Tsuguyoshi M. T. \& Susuki, S. 2011. The utilization of animal product free media and autologous serum in an autologous dermal substitute culture. Journal of Surgical Research, 171: 339-346.

Mujaj S., Manton K., Upton Z. \& Richards, S. 2010. Serum free primary human fibroblast and keratinocyte coculture. Tissue Engineering: Part A, 16: 1407-1420.

Norma Oficial Mexicana NOM-059-ECOL-2010.

Rijken, P. J., Boonstra, J., Verkleij, A. J. \& de Laat, S. W. 1994. Effects of gravity on the cellular response to epidermal growth factor. Advances in Space Biology and Medicine, 4: 159-88.

Secretaría de Medio Ambiente y Recursos Naturales-SEMARNAT, 2003.

Smith, N. S. \& Krausman, P. R. 1988. Desert Bighorn Sheep. A guide to selected management practices. Biological Report Fish and Wild Service, 88: 35-50.

Smith, J. B., Jenks, J. A., Grovenburg, T. W. \& Klaver, R. W. 2014. Disease and predation: sorting out causes of a bighorn sheep (Ovis canadensis) decline. PLoS One, 14(2): e88271.

Soto, M. S. 2006. Monitoreo no invasivo de las etapas reproductivas en borregas cimarrón (Ovis canadensis mexicana) en cautiverio mediante la observación conductual reproductiva y la cuantificación de esteroides fecales. Tesis para obtener el grado de Maestro en Ciencias de la Producción y de la Salud Animal, Universidad Nacional Autónoma de México (UNAM), México. 64pp.

The IUCN Red List of Threathened Species 2011.2.

Thompson, J. G., Gadner, D. K., Pugh, A., McMillan, W. H. \& Tervin, R. 1995. Lamb birth weight is affected by culture system utilized during in vitro pre-elongation development of ovine embryos. Biology of Reproduction, 53: 1385-1391.

Universidad Nacional Autónoma de México. 2009. Con técnicas de reproducción asistida pretenden conserver al borrego cimarrón. Banco de Boletines. Boletín UNAM-DGCS-406.

Vásquez, E. M., Cueva, M. S., Cordero, R. A., Lino, G. M. \& Huanca, L. W. 2011. Evaluación de dos métodos de criopreservación de embriones de llamas sobre las tasas de supervivencia in vivo e in vitro. Revista de investigación veterinaria, 22: 190-198.

Walker, S. K., Hill, J. L., Kleemann, D. O. \& Nancarrow, C. D. 1996. Development of ovine embryos in synthetic oviductal fluid containing amino acids at oviductal fluid concentrations. Biology of Reproduction, 55: 703-708.

Wen, Y., Wani, P., Zhou, L., Baer, T., Madan, P.S., Reijo, P. R. A. \& Chen, B. 2013. Reprogramming of fibroblast from older women with pelvic floor disorders alters cellular behavior associated with donor age. Stem Cells Translational Medicine, 2: 118-128.

Wiedemann, C., Hribal, R., Ringleb, J., Bertelsen, M. F., Rasmusen, K., Andersen, C. Y., Kristensen, S. G. \& Jewgenow, K. 2012. Preservation of primordial follicles from lions by slow freezing and xenotransplantation of ovarian cortex into an immuno deficient mouse. Reproduction in Domestic Animals, 47: 300-304.

Williams, J. B., Shin, T., Liu, L., Flores-Foxworth, G., Romano, J., Blue-McClendon, A., Kraemer, D. \& Westhusin, M. E. 2006. Cloning of exotic/endangered species: desert bighorn sheep. $\mathrm{Me}$ thods in Molecular Biology, 348: 169-82.

Wood, J. M. B., Soldin, M., Shawa, T. J. \& Szarko, M. 2014. The biomechanical and histological sequelae of common skin banking methods. Journal of Biomechanics, 47: 1215-1219.

Yun, W. J., Bang, S. H., Min, K. H., Kim, S. W., Lee, M. W. \& Chang, S. E. 2013. Epidermal growth factor and epidermal growth factor signaling attenuate laser-induced melanogenesis. Dermatologic Surgery, 39: 1903-1911. 